\title{
Biological Evolution on Display: an Approach to Evolutionary Issues Through a Museum
}

\author{
Elisabetta M. Falchetti
}

Published online: 13 April 2012

(C) Springer Science+Business Media, LLC 2012

\begin{abstract}
Biological museums can promote interest in evolution and contribute to its understanding. Modern exhibitions generally emphasize the main concepts of evolutionary theory: biodiversity and adaptation. In 2009 at the Zoological Museum of Rome, to celebrate Charles Darwin, a pilot didactic project was carried out for schools and the general public in order to involve people in evolutionary issues, to stimulate interest and at constructing knowledge about evolution. An exhibition consisting of exhibits and laboratory settings was created. The thematic contexts of the exhibition and the practical experiences were aimed at facing some epistemological obstacles that influence the understanding of evolution and at constructing some "framing concepts" that, on the contrary, could facilitate it. The communicative and didactic strategies were all participative and interactive, based on the personal questioning and restructuring of preexisting knowledge. Behaviors, conversations, and comments by the participants were monitored in order to record any possible change of ideas, interests, attitudes, and learning.
\end{abstract}

Keywords Biological evolution · Epistemological obstacles $\cdot$ Framing concepts $\cdot$ Biological museums . Participative exhibition $\cdot$ Constructivist didactics

\section{Introduction}

Charles Darwin's evolutionary theory brought about one of humanity's biggest cultural revolutions. It represents one of

\section{E. M. Falchetti $(\triangle)$}

Zoological Museum of Rome,

Via Ulisse Aldrovandi 18,

00197 Rome, Italy

e-mail: elisabettamaria.falchetti@comune.roma.it the cornerstones of modern scientific thought and provides a precious conceptual framework for interpreting natural phenomena and life on Earth. The evolutionary vision of the world is fundamental, not only for biological scientists but also for lay people, because it improves critical, causal, historical, and relational skills in mental cognitive processes. Furthermore, it can promote the formation of an ecological conscience as well as an ethical approach toward other living beings in consideration of common relatedness. Therefore, knowledge of biological evolution should be the patrimony of all people. Despite all this, even in countries where evolution is taught, problems are frequently revealed in its understanding and learning.

In the year dedicated to the celebration of Charles Darwin's 200th birthday and the 150th anniversary of the publication of "The Origin of Species," the educational staff at the Zoological Museum of Rome (where the main theme of the exhibits is "animal biodiversity") developed a special project, "Darwin 2009: mega-laboratory on biological evolution," with the purpose of awakening citizen interest in evolutionary theory and its first and most important proponent and — at the same time - of experimenting teaching methods and exhibits on this fundamental theme. This didactic project consisted of the creation of a participative exhibition composed of some exhibits with showcases and laboratories where observations and various experimental activities for schools and the general public could be carried out.

In this paper, the theoretical framework that inspired the choice of the contents and methodological aspects, some practical experiences performed with schools and the general public, and the impact of this didactic project are reported. In particular, the paper will present (1) some examples and considerations of the cognitive background about evolution; (2) the themes selected for this didactic experience and their use as framing concepts; (3) the special 
"learning context" designed in the museum through the setting of the framing concepts, the laboratorial experiences, and constructivist didactic practices; (4) the evaluation and assessment performed on some sample classes chosen from among those which participated in this didactical project; (5) the constructivist methodological fundamentals of this didactical experience and the theoretical frameworks of the evaluation; and (6) some final conclusions on the possible use of this experience in teaching evolution in schools and museums.

\section{Background Knowledge of Evolution}

I will start this paper with some examples of Italian lay people's knowledge of evolution, drawn from the dossier of explorative interviews we carried out during the project. I express our vision that the detected widespread lack of knowledge, conceptual confusion, misconceptions, and naive ideas about evolution have to do not only with school education but also with the lack of other opportunities to gain a deeper knowledge of this theme after school training. In fact, evolution is not an issue covered by the media (with the exception of particular events or periods such as the Year of Darwin), nor for life-long learning projects (with the exception of those developed by biological museums). Aside from when evolution is popularized, the divulgation approach is lacking in didactic attention toward lay people.

Do you know about biological evolution and Charles Darwin?

This question was asked to a sample of about 200 adults of various ages, over the course of this didactic pilot project on biological evolution.

These are a few of the answers we received:

Male, 24, Law student: "Evolution is a consecutive passage of phases or mutations that characterize a species from its appearance on Earth until its complete disappearance, on the basis of empirical and environmental data and experiences. Biological evolution... I don't know... could it refer to puberty or physical growth?! Darwin is the one who gave rise to Darwinism, a theory on the evolution of the species based on the law of the strongest... which resists..."

Female, 23, second year Environmental Science Student: "Evolution is the change of the body structure over a long period of time and as a consequence of the way of life, with an influence on future generations (a shot in the dark). Darwin gave rise to the theory of evolution of the species, but I don't know if he was a biologist or physiologist, I don't know when he lived... he also wrote a book."
Female, 22, Diploma in Linguistics, Pastry Chef: "Evolution of the species, discovered by Darwin, is the change of living beings. I don't know exactly what a 'species' is, but I think they're the classes we separate living organisms into. I think biological evolution is what I said before... if not, I don't know. Charles Darwin is the man who worked towards the discovery of evolution and natural selection."

Male, 19, fourth year student at a scientific high school: "Evolution is the change of certain characteristics due to the disruption of some habits. Biological evolution is evolution from a physical point of view. Charles Darwin should be the man who discovered the evolution of the human species (but what does species mean? The classification of animals I think is subdivided into genus and species, but I don't remember what genus or species are... male and female... species... I don't know)."

In our research dossier, we have a large number of responses similar to these. With the exception of people directly involved in scientific studies or professions, all the other Italian citizens interviewed revealed a lack of knowledge, conceptual confusion, or misconceptions and naive ideas. The sample is not very large, but it is enough to suggest a worrying nation-wide ignorance regarding biological evolution. Similar conceptual problems were reported in numerous studies conducted in other countries throughout the world as well; see, e.g., Prinou et al. (2008), who cite an extensive bibliography on the issue. The knowledge of evolutionary phenomena is entrusted to scientific teaching, which, in Italy and elsewhere, faces many difficulties, such as few available dedicated hours and tools, few opportunities for teacher training, and few possibilities for integrative curricular experiences. Teaching is generally theoretical and based on the historical aspects of evolutionary theory (history of evolutionary thinking; from Lamarck to Darwin to modern evolutionary biologists). Moreover, in the last few years, biological evolution has occupied less and less space in our curricula. This fact is worrying because only a valid teaching approach can introduce the theory and help to face the difficulty of the theory itself. Mayr (2004) points out that, in reality, we should consider evolution inclusive of five theories. In fact, the understanding of biological evolution requires not only basic scientific knowledge about the organization of living beings but also a good mastery of the concept of species, classification criteria, principles of genetics, and also of the nature of science, as noted by Nadelson (2009). Moreover, understanding evolution is made more difficult by a quantity of conceptual and epistemological obstacles, like finalism (Aroua et al. 2008) and determinism (Nadelson 2009) caused by social representations, common education and cultural, emotional, linguistic, 
philosophical, religious, and logical problems, as tested, for example, by Bertolini (1992), Maniaci (1992), Falchetti et al. (1999), Kyle (1994), Mead and Scott (2010), Richards (2008), Sinatra et al. (2008), and Tranchida (1996). These obstacles prevent the shift from common sense and lay knowledge to scientific understanding. Simple "explanations" or teaching that simply transmits information (as is commonly proposed in scholastic lessons, but also in museum exhibitions and programs) are not sufficient to overcome the numerous conceptual, cognitive obstacles. On the other hand, it is possible to memorize some evolutionary concepts (and it happens commonly in schools), but it is difficult to learn significantly and to transform them into "personal culture," i.e., according to Bruner (2002), using something learned to interpret the world and create new knowledge and personal ideas. This is confirmed by the fact that, even after scholastic teaching, people (young and adult) tend to provide teleological or Lamarckian explanations for evolutionary processes and persist in thinking in a finalistic and deterministic manner, as tested, for example, by Bishop and Andersen (1990), Demastes et al. (1995), and Falchetti et al. (1999). These models of thinking are probably closer to common sense and usable without having a grasp of scientific knowledge. Misconceptions and conceptual difficulties have also been verified in teachers-e.g., Maniaci (1992) and Nadelson (2009) — which can be influenced also by religious beliefs as tested by Valente et al. (2008). Even textbooks often contain misconceptions about Darwin and his ideas (Rees 2007). Teaching and learning about evolution remains a problem; therefore, experiments should be done using new conceptual pathways and didactical models.

Biological museums are involved in most scientific research in evolutionary biology and are interested in public naturalistic education (scholastic and life-long education), including evolution. As a consequence, they are in a singular position and are responsible for observing and studying the obstacles that hinder the understanding of evolution and for proposing innovative techniques to answer the challenge.

\section{Selection of the Themes and Issues, Cognitive Obstacles, and Framing Concepts of Evolution}

The starting point of the theoretical frameworks of this didactic project was the awareness of some common conceptual obstacles about evolution (recognized also in the explorative interviews performed for this project). Among these, the difficulty of imagining the unverifiable evolutionary changes of environments and living beings over geological time was recorded (in fact it is difficult to master spatial and temporal scales). It is not simple and spontaneous to imagine that environments and living beings change, since the perceivable changes that happen in a human life span are generally physiological ones occurring throughout a life cycle: birth, growth, sexual maturity, and (old age) death. Another conceptual obstacle is connecting (without finalistic interpretation) shapes, structures, physiological functions, and behaviors of living beings to environmental fitness and seeing the reciprocal ecological interactions between environmental factors and living beings. It is unlikely that, without valid teaching, people will consider environmental elements "ecologically" as dynamic and active factors. The environment is commonly seen as a static "space" or "place" in which our lives and activities happen (BoillotGrénon 1999; Caravita 2006; Falchetti and Visco 2008; Falchetti 2010). Another obstacle is perceiving and cataloguing the diversity of living beings and its different forms/levels of organization (Bruckmann 2009; Falchetti 2006). Lay people classifications of biodiversity generally are based on practical and daily use of natural resources (like berries, shellfish, healing herbs, etc.) or to large categories (birds, plants, insects, worms, etc.). If it is difficult to perceive and classify biodiversity, it is still more difficult for lay people to imagine and explain its origins. According to popular cultures, the origin of biodiversity is explained by means of various traditional myths or cosmogonies based on religious doctrines, among which is also divine creation. In default of convincing scientific knowledge, these explanations are permanent. Some of these beliefs, such as creation, remain even after scientific instruction (Valente et al. 2008) and can produce further conceptual obstacles.

On the basis of these considerations in the "Darwin 2009" project, rather than explain the formal contents and fundamental assumptions of evolutionary theory directly, I tried first to make some of these obstacles more approachable thanks to the Museum's resources and special didactic strategies. The purpose was to facilitate the introduction to evolution by stimulating conceptual change of previous ideas and beliefs with the help of framing concepts to which evolutionary phenomena could be connected. Framing concepts are ideas or mental images which have the potential to operate as cognitive organizers, to promote the restructuring of cognitive system, and to connect pre-existing knowledge to the new (Gagliardi 1986, 1989). The theoretical and didactic assumption of this project was that before the theory's study, a mastery of these concepts could make easier a meaningful learning by improving learners' ability to think about evolution, by changing their approaches and conceptions, beginning from previous beliefs and knowledge. According to Ausubel (1983), learning is meaningful only if new knowledge is connected to the pre-existing.

Four assumptions were considered as framing concepts to approach evolution: 
- Living beings and natural environments change and are changed repeatedly over time. This can be a framing concept to understand evolutionary changes and to wonder how they happen. Besides, it can help to overcome the conceptual obstacle of considering evolutionary change as "necessary or voluntary"-recorded, for example, by Bardapurkar (2008) — or finalistic (Aroua et al. 2008). In lay knowledge and naive ideas, "fixism" is easier and more coherent with creation (Cuvier teaches...). So it could be convenient, before teaching Darwinian theory, to emphasize change and to provide some evidence of it, in order to make it acceptable that all living beings evolved in the past and are evolving in the present.

- The environment and living beings interact. All elements in the environment (including living beings) are dynamic "agents," "factors" that influence each other. This constitutes a framing concept to understand adaptation and natural selection, given that it is not spontaneous to connect shapes, structures, and behaviors of living beings to environmental factors and, vice versa, environmental organizations and transformation to the living beings. As a consequence, it could be didactically convenient to provide experiences that favor this reflection and help learners to connect shapes, functions, and behaviors with environmental fitness.

- Diversity is an emerging property of living beings and it exists at all different levels of life organization. The ability to perceive diversity and the awareness of biological diversity can facilitate the comprehension of evolution. Without these compentencies, it is impossible to recognize the potential and the result of evolutionary processes in biological diversity (new species and adaptations, new vital strategies). The "biodiversity" scientific model is complex; it is connected with genetic differences (genetic biodiversity), inter- and intra-specific differences (taxonomic biodiversity), and ecosystem-landscape differences (environmental biodiversity). The comprehension of this model depends not only on the personal perception and awareness of diversity-on social cultures-but also on the ability to organize living beings in categories outside common sense, and finally on the mastery of evolutionary classification (and genetics). We can spontaneously perceive macrodifferences among living beings. However, only through teaching can we learn different categorizations of diversity to understand scientific concepts (for example, the species concept), to attribute to biodiversity a role in evolution and fitness, and to questioning oneself about the origin of this diversity.

- Intra-specific diversity exists; genetic diversity is responsible for individual diversity, the genetic code is universal and explains the "unity and diversity" of living beings. The awareness of intra-specific biodiversity is a key to understanding Darwinian "variability" and the action of natural selection. The genetic fundamentals - which can be learned only by teachingare essential to master in order to understand postDarwinian interpretations (genetic mutations and causality, genetic heredity, etc.) and can support the understanding of the common origin of living beings.

\section{The Learning and Experiential Context of "Darwin 2009" in the Museum}

Biological museums can be considered learning environments that facilitate the understanding of scientific concepts because they stimulate interest and motivation, personal inquiry, and reflection. In modern museums, natural specimens, objects and samplings are displayed following standards that emphasize the diversity of life and the relationships between living beings and their environments. For example, many exhibitions show different specimens belonging to the same species to facilitate the comprehension of intra-specific diversity by the comparison of individual traits, as other exhibitions show different levels of taxonomic-inter-specific biodiversity. "Dioramas" reproduce natural environments to emphasize diversity in biotic communities (ecological diversity). Other exhibits show adaptations to illustrate the influence of ecological factors and natural selection. Many important naturalistic museums have dedicated entire exhibitions to biological evolution (e.g., London's Natural History Museum with its Darwin Center and Paris' Muséum d'Histoire Naturelle with its "Grande Galérie de l'Evolution"). Therefore, in "Darwin 2009," the Zoological Museum was considered a facilitator in approaching evolutionary issues and was exploited for its unique resources (exhibits, natural specimens, scientific instruments, etc.) to stimulate interest, questions, and comprehension without copying scholastic teaching styles.

A special learning context and setting were organized in a large hall of the Museum to display the four conceptual frameworks by means of museum expositive facilities. Darwinian issues and the four framing concepts were transformed into a narrative pathway by means of some exhibits with natural specimens, models, images/ pictures, and books. According to Bruner (2002) and Bateson (1999), the narrative dimension is more suitable because we all think through stories; narrative weaving gives sense to our life.

All the exhibits were not separated spatially and visually in order to favor a perception of continuity and interconnection among the various themes and experiences, like a "web of knowledge." 
Darwin and Evolution Knowledge should be contextualized. Context gives meaning to the educational experience (Bateson 1999). The contextualization of a cognitive experience, a sort of setting or background, is essential to direct and facilitate learners to recall pre-existing ideas, to connect those to the new ones, and to move from common to scientific perspective. In "Darwin 2009," a very short reminder of Darwin's life and his scientific works provided the context of comprehension (Bateson 1999) for the cognitive experience and learning environment.

In a museum showcase, some of Darwin's portraits and short biographic notes, as well as one copy each of the books The voyage of the Beagle and The Origin of Species, were put on display. In another showcase, one of the case studies reported in The Origin of Species, the Viola Tricolor and the bumblebee, was shown through the display of the natural specimens and the original Darwinian description. In another showcase, some naturalized specimens described by Darwin (a Rhynchops nigra, an armadillo, and an iguana) were displayed along with panels reporting the original Darwinian explanation, to exemplify his adaptive interpretation. Some very incisive short passages of Telmo Pievani's book Introduction to the philosophy of Biology (Pievani 2005) stimulated some reflections on the cultural value of evolutionary theory. To reconnect Darwin to the visitors" "now" and to their real experience, an exhibit was created showing some examples of the present evolutionary research at the Zoological Museum. This exhibit aimed also at confirming the relevance of Darwinian theory and its impact on modern science and at explaining why a naturalistic museum was paying homage to Darwin.

In this section of the exposition, visitors (students and general public) were received by museum educators and began their visit; they were free to explore the showcases, to converse with each other and with the museum educators. The latter invited visitors to write their ideas about Darwin and evolution (if any) on special sheets of paper. This strategy aimed at facilitating visitors in understanding the conceptual context (an exhibition dedicated to Darwin and his scientific work) and at reminding them of their pre-existing knowledge in this field. The completed sheets remained available to the visitors to verify eventual changes of ideas at the end of the visit. After this initial exploration, visitors were guided by museum educators through the four exhibits by means of which the four conceptual frameworks were put on display, and there they were engaged in practical experiences and debate.

\section{The Four Framing Concepts on Display and the Practical} Experiences The four framing concepts (see above) were presented in as many exhibits composed of single showcases and laboratory spaces for practical experiences.
The exhibits did not contain panels with mere information, "pre-packaged answers," or definitions to memorize; rather, they were labeled and structured to encourage the use of the imagination, of questions, and curiosity on the themes of the framing concepts by showing specimens, images, and models. The brief texts simply provided starting points to spark personal reflection or short notes for the identification of the objects on display. Images and pictures were also displayed, emphasizing their communicative and expressive values rather than as explanations and information (as commonly happens in books and museum exhibitions). The four exhibit areas were equipped with stopping places and empty exhibition spaces, to be filled with participant creations: drawings, diagrams, and models. In each exhibit, visitors observed biological specimens, saw simulated scientific research; and discussed the themes in working groups, helped by museum educators. The latter acted as "organizers" of visitors' didactical pathway, stimulating questions and debates, guiding experiences and research:

- For reflecting on change over time (first framing concept), an exhibition was created with showcases of fossil specimens; and with the reconstruction of a small paleontological laboratory, complete with a reproduction/simulation of a paleontological dig with fossils. Here visitors played a role/simulated paleontologist's study methods and the practical work of digging. They observed the fossils found in the dig and discussed research, questions, and hypotheses about the biological traits and life environments of these organisms. Diagrams, drawings, molds, and models were created by visitors to reconstruct fossil animal shapes and paleoenvironments. These visitors' products enriched the exhibit, creating a "living" exposition.

- The second framing concept was displayed by an exhibit entitled "Life Forms and Environment: Insects as a Case Study." The study of evolution "by example" (Goldstein 2008) had already been done successfully in the Zoological Museum (Maniaci 1992; Falchetti et al. 1999), and we verified that reasoning over observable and concrete cases stimulates interest and questioning and facilitates understanding of evolutionary issues. In "Darwin 2009," I chose insects because these animals show original, extremely efficient, and easily observable adaptations; therefore, they constitute an exciting and accessible example.

The main concept in this section of the exhibition was the relationship between structures, functions, life environments, and fitness. Here visitors played the role of an entomologist. They observed numerous 
naturalized specimens and various models of insects, compared structures, and debated on the fundamental and most successful elements of the evolution of insects: the exoskeleton, wings, mouth apparatus, etc.

- Several exhibits were dedicated to biological diversity ("The Diversity of Life: A macro and micro vision"); many animal specimens of different taxa were displayed to show inter-specific biodiversity and suggest the abundance of different life forms. One exhibit was dedicated to the vertebrate classes, generally more recognizable by visitors because more present in their daily lives. In this section, visitors described and compared differences/similarities; and traced hypotheses to explain them and to find relationships among taxa. The museum educators invited the visitors to classify the specimens, stimulated the debate on common classification criteria and on their limits, and suggested the scientific approach based on systematic phylogeny. Particular attention was given to "not visible" bio-diversity (Protozoa, Protophyta, etc. but also animal and vegetal tissues, in order to verify similarity/diversity among cells) through microscopic observation, guided by museum educators. This experience stimulated reflections not only on common origin and relatedness of living beings but also on their diversity and its origin. Finally, various specimens of different species of small mammals were at visitors' disposal to freely create their own exhibit with the commitment to illustrate cases of biodiversity.

- For the last framing concept, in an exhibit entitled "Variability, Genetic Diversity and Evolution" numerous mollusk shells, specimens of lepidopteron, and other insects were displayed. Models of chromosomes and DNA were also put on show. Intra-specific diversity was at the core of this section. For all visitors including students, the laboratory activities consisted of the observation of intra-specific phenotypic biodiversity of the specimens exposed. In order to associate phenotypic diversity with genetic diversity, the middle and high school students in addition observed at the microscope some chromosomes from onion roots, and only the high school students observed the extraction of DNA from some fruits.

The didactical pathway ended with a second, and more aware, visit to the section dedicated to Charles Darwin and a semi-free visit to the other halls of the Zoological Museum; the final message was that the explanation offered by Darwin, with his theory of biological evolution, is still the best one possible for science.

School visitors performed the didactical experiences in one or more visits (primary school one visit, approximately five hours; middle school three visits, approximately
15 hours; high school two visits, approximately 12 hours). The general public and families participated in the weekend laboratories (approximately four hours for each visit).

\section{Evaluation and Assessment}

As explained above, the theoretical didactic assumption of this experience was that a mastery of these four concepts could facilitate meaningful learning of the evolutionary theory by improving the learners' ability to think about evolution, changing, or improving pre-existing approaches, ideas, and knowledge. As a consequence, in order to evaluate the effectiveness of this experience, it seemed appropriate to investigate eventual impacts on students' mental connections and understanding about evolution, their change of ideas, new knowledge, and approaches.

A small sample of pilot classes (three of primary school, total student number 71 , aged 9 to 11 ; three of middle school of which two classes included students aged 12-13 and one class $14-15$, total student number 70 ; two high school classes, total student number 47, aged 16-17) were followed and monitored by myself and constantly observed by another researcher.

Different evaluation strategies were utilized that will be discussed in the next section. Tools for evaluation were constituted by the following:

1. The brief notes compiled in the Darwin exhibits before the beginning of the guided experiences/visits to the other sections of the exhibition: Primary school students were asked only about Darwin; middle and high school students were asked about Darwin and evolution ("your ideas about evolution"), presuming some pre-existing beliefs or school knowledge about this topic. Compilation of the sheets was free in order to allow students to express the main (more frequent and presumably more "internalized" and stable) concepts that they associated spontaneously to evolution.

2. Personal individual notebooks containing open-ended questions (a sort of semi-structured interview) and free space for comments and drawings that students compiled in the museum before, during, and after their observations and practical experiences. The compilation "before" aimed at activating students' interests, to recall and record in the notebooks their pre-existing knowledge. The compilation "during" aimed at directing students' attention at the practical and mental passages of their experiences and at their personal reflections. In fact, I considered it fundamental to make them aware of their own learning processes. At the same time, this procedure allowed me to check what was happening constantly, which cognitive emotional processes acted; and finally to know students' beliefs, values, feelings, 
interests, and ways of experiencing the various activities. The compilation "after" aimed at recording new interests, knowledge, and learning; at confirming perceptions of cognitive or affective changes; at highlighting favorite activities, the personal meaning, and importance attributed to them; and finally, at recalling the topics and the performed activities. For these aims, the notebooks contained questions regarding what they were doing, what they had done, what they believed they learned, what they considered more interesting, if their ideas changed in any way, etc. From the answers given by the students, I have extracted "key words" or "key concepts" and classified them into statistically significant categories (the percentages are rounded to unitwhole numbers). I have compared the "unclear/doubtful" categorization with another researcher. Students' comments and drawings were also analyzed.

3. The collective discussions before, during, and after each practical experience and observation were analyzed. The more significant points of the conversations were extracted in order to reveal the development of the educational processes.

4. Final tests - only for the middle and high school studentsrequiring conclusive reflections about the performed experiences, new knowledge, change of ideas, etc. were given to be compiled in the museum or in class. The tests were different for the two school levels and consisted of open-ended questions connected with evolutionary issues. A "long-term test" was given only to the middle school students aged 13-14 (III class) to evaluate eventual further change or internalization of knowledge three months after the end of the Museum experience.

5. A semi-structured written interview was given to the teachers at the end of the school year.

6. Ethnographic observations of the students and teachers during their activities were performed; main behaviors and attitudes were observed and recorded constantly by another researcher.

Evaluation of the Free-Compiled Sheets About Darwin and Evolution From the pre-experience sheets about Darwin and evolution compiled by the middle and high school students, nothing new emerged when comparing them with the concepts and stereotypes abundantly recorded in other research studies.

From the analysis of 75 extracted key words in the sheets of 70 middle school students (some students wrote more than one definition), it was found that $27 \%$ referred to evolution as "development," $24 \%$ as "change," $12 \%$ as "growth," $9 \%$ as "transformation," $7 \%$ as "life origin," followed by passage, progress, modification, etc. (21\%); only two students wrote "adaptation" (to the climatic change, or to the territory), but only one of these referred to it in a voluntary sense. In 12 cases (on 75; corresponding to
$16 \%$ ), evolution was emphasized as "positive" (improvement or progress); in three cases, negative and positive; in one case as indifferent. For these students, evolutionary changes involved "mental and physical characteristics" or "intelligence and knowledge" (clearly referred to man); secondarily, the ways of living, physical structures, ways of thinking, etc. Changes included man (29\%), animal and plants (19\%), followed by "nature" (6\%), life (6\%), "forms of life," "living beings and species," "body shapes," but also Earth, time, science, and cultures, etc. (40\%). The changes happened "over time" (75\%), but also "continuously," "throughout life," "over the years," "from the origin of creation," etc. (25\%). Key concept words like extinction, diversity, and natural selection were generally lacking. The middle school students clearly showed some confusion in defining the evolutionary processes due to the use of the term "evolution" in other disciplinary fields such as history (in which they use this term to mean human progress).

Among the high school students, no significant conceptual differences were noted except in the use of "more expert" language (for example the use of the terms adaptation and genetic change). Also for these students, the main key words were "change" (33\%), "development" (4\%), "transformation" (4\%), "improvement and progress" $(18 \%)$, other things $(9 \%)$, but also life origin $(12 \%)$, adaptation (about 12\%; in four cases in a finalistic way) or generically "process" (8\%). In 11 answers, it was specified that "over time," "living being or species" (15 cases), but also "Earth, organs, human beings, environment etc." evolve. In three cases, evolution was emphasized as positive change.

Charles Darwin was well known by the primary school students. All of them were able to "narrate" in some way about Darwin's life, of which they had a romantic and enthusiastic idea. The main key concepts were "the voyage" and "the naturalistic studies." The middle and high school students had similar ideas and ways to describe this figure. They added generally, "A great scientist who wrote fundamental books," "who changed the previous idea about animals and life on Earth," and "A great man with a high level of culture; he contributed greatly to scientific knowledge." Some high school students quoted The Orgin of Species and related Darwin generically to "evolution" or evolutionary theory by adaptation (one student). Evolution in some cases was "discovered" by Darwin, after his "wonderful" voyage.

Evaluation of the Experiences Connected with the First Conceptual Framework (Living Beings and Natural Environments Change and Are Changed Repeatedly Over Time) The simulation of digging up and the observation/study of the fossils stimulated many questions about differences of living beings and environments in the past and present, 
promoted the imagining of paleoenvironments, and suggested extinction and change in organisms. The big research question "What would a paleontologist know?" corresponded to the students' questions that arose; for example (from the conversations and notebooks of primary and middle school students), "What animal was it? Why is it here? Where did it live? How was it shaped? When did it live? Were there others like it? What were the causes of its death or extinction? Did they all die (the individuals of the same species) or just this one? What was the environment it lived in? Why did it became extinct? Did it have any relatives?" etc. The variety of the observed fossils gave an example of the diversity in life forms and of the abundance and richness of this phenomenon. In all the notebooks after this experience, many extinct animals were mentioned, and extinction was described as a recurrent phenomenon ("Then many other animals, not just dinosaurs, became extinct," for example, in primary school; "Many changes happened in the past and they continue now," primary and middle school). Extinction was never mentioned in the pre-experience sheets. An interesting conceptual enrichment emerging from the discussions, notebooks, and final tests was the connection between extinction and the environment; all the students referred to environmental changes and lack of fitness as causes of extinction: Now environment was playing a dynamic and significant role, and it was not only a backdrop. In particular, from the notebooks of the middle school students, I have extracted 75 key concepts about this topic (some students gave more than one answer). Extinction was connected to the environment and its changes and consequently to lack of resources or fitness $(64 \%)$, to scarce reproduction $(15 \%)$, to evolutionary processes $(5 \%)$, and to other causes $(16 \%)$. Some answers were expressed in a naive way; for example: "Then animals became extinct because they were not fit for their environment...," "It didn't change when its environment was changing," "They can't survive if they don't change...," "If they couldn't change then they became extinct," and "They're not always fit." Some of these statements seem to me a valuable acquisition because the comprehension of relativity of fitness is difficult for young students. Also all high school students related extinction to evolutionary processes, environmental factors and fitness (nearly 100\%; only one student related extinction to catastrophic events, such as meteorites).

The conversations and questions about extinction revealed that the "paleontological" experience was suitable to stimulate reflections on the "potential," not "willingness" or "obligation" of evolutionary change and to appreciate the explanations provided by evolutionary theory. In the course of our/their conversations and in their notebooks, the students emphasized that the comprehension of extinction mechanisms was clearer and that they had found it difficult to associate extinction to evolution because they looked at evolution as improvement or positive change.

This experience was stimulating also for skills, imagination, creativity, and for reconnecting previous knowledge about paleoenvironments (one of the key didactical points: environments change). Descriptions, drawings, and collective posters revealed this, and many research studies about this topic were performed in classes or in the museum. At all school levels, splendid and exhaustive drawings and environmental models were produced.

From the affective and emotional point of view (attention, participation, interest, and motivation), all students (100\% primary, middle, and high school) were able to describe the activities performed (during and after) exactly and accurately and to explain their aims. They wrote down their main interests about each topic and experience in the notebooks. For the primary school, the dig and the study of the fossils was the preferred activity. In their notebooks, I found many attempts to reconstruct paleoenvironments and fossil animals. Among the changes of ideas were: "environments change, they were different in the past" and "palaeontologists study the change of living beings in the past."

From the middle school answers, I extracted 72 key concept words, representative of the students' main interests. These can be summarized in three fundamental categories of interests: specimens (e.g., fossils, animals, etc.), $40 \%$; activities (e.g., "to study fossils," "to be a paleontologist," "to prepare a poster with the fossil bones") $36 \%$; concepts (e.g. "the way of observing of the scientist, which is more objective") $20 \%$; but also simply "Darwin" (4\%).

For the high school students, the main interest was connected with the fossil specimens and their observed characteristics (about 100\%; only one student wrote as the main interest "adaptation"). The students showed a positive and conscious perception of their new knowledge acquisition or conceptual change. The primary school students generally declared, "I have no changed ideas but I have learned new things..." about Darwin, fossils, paleontological work, diversity, extinction, etc.

From the notebooks of the middle school students, it was found that $61 \%$ of the students changed some idea. Analyzing 43 explicit conceptual changes in detail (many students wrote simply "My ideas have changed ..." or "More than changing I've learned new things" or "I acquired new ideas"), I noted three fundamental categories of changes: knowledge, interests/attitudes, and motivation and concepts. The changes in knowledge constituted 58\% (e.g., "My idea about the concept of extinction have changed; at the beginning I had a vague idea about this topic; now I know that many species became extinct and could become extinct for environmental change, lack of food, scarce opportunities for reproduction, lack of fitness..."; "Curiosity and questions have come up that I didn't have before"; "I've clarified 
some point I thought I knew, but now I know that it wasn't exactly right"; "compared to before... I think that in the vegetable and animal worlds there are still many secrets to be revealed"). The changes in interests, attitudes, and motivations were $16 \%$ (e.g., "I thought that it was boring to study fossils, but after this experience I've understood that it is very interesting... mainly to discover the fossils' ages... why they became extinct, but also to know where they are and how to find them"). The changes in concepts were $26 \%$ (e.g., "It is necessary to be interested, to investigate and study a matter more deeply in order to understand things better, and not to stop on the surface"; "I've understood the role of paleontologists and paleontology"; "I changed my idea about fossils"; "Yes... that extinction is a passage, a process of evolution").

The high school students said they found confirmation of what they already knew. More than having changed ideas, they said they acquired new knowledge. Among the changes was "My ideas changed about how we can study Darwin's history and research."

As a result of ethnological observation of the students' behaviors and attitudes, participation of the primary and middle schools can be defined as "enthusiastic." It was surprising to see how much attention, care, and accuracy all the students showed as they worked. The middle school students, who had already been taught about evolution, appreciated the simulation of the paleontologist and confirmed their engagement in the activity. The high school students seemed initially more uncertain and embarrassed, but they were nevertheless engaged by this experience.

\section{Evaluation of the Experiences Connected with the Second Conceptual Framework (The Environment and Living} Beings Interact) The main concept which emerged during and after the insect observations was connected with "functions that the various body parts have" and their relationships with the environment. After initial superficial observations of many insect specimens, students were invited to observe and describe "as an entomologist" also by means of stereomicroscopy and magnifying glasses and to draw. The question, "what would an entomologist know about this animal?" changed the perspective and knowledge context. The students' questions (what it is... where it lives... how it is structured... what it eats... if it is male or female... what antennas, wings are for... something about its colour patterns... why the legs are different... long... with hairs, etc... if it is dangerous... why it has a long body, etc... why it looks like... a leaf... a stick...) helped to guide the students' attention to scientifically interesting details. Many surprising discoveries and many questions came up from the observation of body structures. The trend to interpret structures and shapes in relation to the environment and adaptation emerged in all the students' discussions and notebooks. Questions (or observations) were generally expressed in the style of "What is it for?" Right answers were found by means of the collective debates and the suggestions of the museum educators. The term "adaptation" was soon introduced by even the youngest students (association with previous knowledge or immediate learning?) to explain the relationship between shape, function, and environment or improvement of fitness, generally in the form of "Did it adapt?" Discussions with the older students were stimulated by the museum educators concerning linguistic and conceptual implications ("What is it for?" or "It adapted") to highlight (mainly for the middle and high school) their tendency toward a finalistic interpretation and to introduce the casualty/contingency in evolution.

The impact of the insects was strong. Many students concentrated their attention mostly on these exciting animals. The study of this zoological group was shown in the notebooks to be among the most appreciated activity. From the middle school notebooks, I have extracted 70 key concept words to analyze the main interests. It showed basically a distribution within three categories: specimens and their biological characteristics (52\%; e.g., "Insect body and wings," "Coleoptera"), activities (40\%; e.g., "to observe insects," "to study how insects are made"), concepts (7\%; e.g., "diversity of butterflies," "Coleopteran adaptations like elytrae," "mimicry of the leaf insect"), and "all" (1\%).

Also the high school students were found to have been highly interested in insect biological characteristics and adaptations. Macro- and micro-observations, descriptions, and drawings were accurate and precise in all the students (100\%); "I studied insects like an entomologist and I liked it"; this was a recurrent declaration made by primary school students that implied also a sort of awareness of the scientists' particular ways of observing and interpreting.

The perceived and declared changes referred to knowledge. Among 40 specified changes by the middle school students, $73 \%$ referred to changes in knowledge and $10 \%$ in general concepts, but also to changes in attitude and behaviors, interest, and feelings toward the insects (17\%). Many answers and comments were similar to these: "Before this experience they made me sick," "I thought they were disgusting and now I find them interesting," "Before I was afraid of insects," and "I didn't have the courage to look at them." However, some comments also indicate interesting cognitive changes; for example, "I didn't think insects were so complicated," "I didn't think that all the structures worked for something," "My idea about how complicated the insect body is changed," "I've learned some points of view on how you can see an insect," "I've learned that all insects have some particular characteristics," "I was struck by insect diversity, especially that of the butterflies," "I was interested mainly in how coleopterans adapted by equipping themselves with armour," "I've learned something about 
camouflage techniques," and "I've learned that different forms and functions exist, not only for camouflage."

A frequent declaration among the primary school students was, "None of my ideas changed because I didn't know anything about these topics" but also "My ideas haven't changed, but now I have a lot of questions."

All the students declared that their knowledge had improved, revealing their conscious perception of new acquisition. By analyzing a total of 67 key concept words of the middle school students, it was found that the main acquisitions were concentrated on knowledge (54\%, e.g., "the insects' body characteristics and their functions... e.g., antennas, hairs, eyes, wing reticulum, colour patterns, mouth apparatus, nutrition”; “...mimicry techniques” etc.); after, on skills $(25 \%$, "I've learned some different points of view for seeing insects"); finally, on general evolutionary concepts ( $17 \%$, e.g., "adaptation of insect body," "advantages of insect mimicry," "functions of insect hair," "adaptations of the body shapes and functions," "that every insect characteristic is important for its life") and attitudes (4\%; e.g., "I've learnt to observe, distinguish and analyze").

The high school students were asked about this theme in the final test. Their trends were similar to those of the middle school students. Main interests were found to be insect mimicry and sensorial functions of antennas, hair, etc. All the students tried to interpret insect structures and functions in terms of adaptations.

Evaluation of the Experiences Connected with the Third and Fourth Conceptual Frameworks (Diversity Is an Emerging Property of Living Beings and It Exists at All Different Levels of Life Organization) (Intra-specific Diversity Exists; Genetic Diversity Is Responsible for Individual Diversity, the Genetic Code Is Universal and Explains the "Unity and Diversity" of Living Beings) The word diversity never appeared before these practical experiences (with the exception of some students who cited in their notebooks the "diversity of insects" after the observation of this animal group). After the work on the third conceptual framework, the term diversity was used fluently, easily, and with awareness by the students in the course of the debates. From the analysis of the notebooks, it was found that all the students $(100 \%)$ noted "We observed diversity." Many students specified among the new learning "animal diversity and cell diversity." In particular, from the middle school notebooks, I have extracted: "We talked about diversity within the same species" (13\%)" and "... about cell diversity" (13\%). Among the elder middle school students, $80 \%$ wrote about intraand/or inter-specific diversity in connection with evolutionary processes; the remaining $20 \%$ connected diversity with other causes (e.g., sexual reproduction).

The microscopic observations had an unexpectedly strong impact. The scholastic (and media) habit of speaking about "the cell" probably prevent the idea of cell diversity as well as of hierarchical continuity of diversity at various life organizing levels. Through guided micro- and macroscopic observations, students discovered and verified not only similarities and the sharing of some fundamental characteristics in macro and micro living beings (for example, cell organization) but also differences in the same organism (for example, intra-cell diversity) and among different species (personal verification is more effective than book or teacher assertions!). The main questions that arose for the primary and middle school students were about the causes of similarity and diversity. These questions displaced their lay knowledge and stimulated reflections (or hypothesis in the youngest students) on the similarities that denote common origin and relatedness of all living beings ("Today we've learned why all living beings are composed of cells"; "They all have cells because they are all related even if they are different, because they come from the same organism" (sic! in Primary school); "They all come from some initial cells"). Many students wrote about initial cells or one cell from which all living beings came.

The other most frequent "appropriate question" at all the scholastic levels was about the origin of diversity (from what... why is it... what is the origin of this diversity? How did they all become different?), that allowed us to introduce or recall the evolutionary explanation of the origin of diversity. "Evolution and common origin" was the explanation for middle and high school: "Different shapes/ appearances but similar basic characteristics explainable by evolution." Evolution explains and interprets biodiversity. In the final test, the students attributed biological diversity to "evolution." Some students (12\%) associated the origin of diversity to sexual reproduction.

Some particular tautological explanations were recorded (that emphasize the impact of the discovery of cell diversity): "Diversity comes from cell diversity"; "Diversity exists because cells are different"; "Diversity is produced by the association of different cells"; "Organ diversity comes from cell diversity"... but also "Animal diversity comes from a cell that differentiates itself"; "Diversity is in all living beings."

Another considerable outcome during the experiences was the evidence of the necessity for an agreement on classification criteria, considering the difficulty in forming reliable taxonomic groups (By color? Shape? Or other?). The "kinship" criterion emerged in the debates, which allowed us to reconnect (with the middle and high school students) the formal/conventional taxonomic categories with the evolutionary phylogenetic classification. It appeared clear that many students knew the Linnaean categories, but they did not understand evolutionary relationships among the taxonomic categories. 
The attempt to create examples of small mammal biodiversity and to explain their criteria stimulated students to identify similarities or differences and to explain them in terms of adaptation and relationship to different environmental needs. In particular for the fourth framing concept, the students at all school levels participated in the classification/systematic exercises. Observation of intra-specific diversity was exciting for all of them ("I enjoyed classifying different species of shells and different or similar insects"). In the notebooks, all the students emphasized this concept (for example somebody wrote "I didn't think that so many species of butterflies or mollusks existed"). It appeared clear that before, no one had a real concept of the quantity of intra-specific "variability" or even of the quantity of taxonomic biodiversity.

For the youngest students, this experience had the aim and effect of helping them to become aware of the variability of external characteristics. For the middle and high school students, the observation of chromosomes acted as a bridge which connected to genetic diversity. In both experiences about biodiversity (third and fourth conceptual framings), a good deal of difficulty in mastering the species concept came up. Moreover, only in one middle school class (elder students) the problem of reproductive isolation mechanisms was brought up, and some students wrote in their notebooks that they finally understood "that" and "why" males and females coming from different species do not mate. This is a real problem to consider because without a comprehension of reproductive isolation, it is difficult to understand evolution.

Among the high school students, I noted a disconnect in associating genetic mutations to diversity, notwithstanding the school teaching. Perhaps it is not so automatic: Theory is one thing, application and practice is quite another! After this experience, the high school students remembered mutations and linked them to new evolutionary views.

The answers given in the middle school notebooks were analyzed. Among 62 key concepts, the main interests specifically declared were: activities $(40 \%$; e.g., "to observe and talk about variability and diversity of different animal species"; "to observe and classify shells"), topics and concepts (35\%; e.g., “...biodiversity and variability. I've found the answer to all my questions"; "When we talked about biodiversity; but overall to know how cells developed and how the different world species originated... and when we talked about biodiversity"; "diversity, despite living beings' common origin..."); and finally, specimens (23\%; e.g., "different types of shells"; "the many butterfly species"); but also "all" ( $2 \%)$.

Changes of ideas were declared by $80 \%$ of the middle school students. Among 37 specified changes (many students wrote simply "Yes, a lot of my ideas have changed"), $32 \%$ regarded intra- and inter-specific diversity. From the analysis of the 37 key concepts, it was found that $84 \%$ of the changes regarded knowledge (e.g., "My ideas have changed about the meaning of the term evolution, on biodiversity and natural patterns"; "... on the common origin of living beings, on the impossibility of the reproduction among different species, on intra-specific variability"; "I thought that cells and bacteria were not living because they do not move and I didn't know that a yeast is a mushroom"; "I didn't think that so many butterfly species exist"); $3 \%$ of the changes regarded interests and attitudes (e.g., "I've changed my idea about my interest in many things that before didn't interest me"); $3 \%$ activities (e.g., "...on the observation of cells and animals"; "On the way to obtain wider knowledge"), and about $10 \%$ other things.

About $86 \%$ of the students declared they learned something new. From the analysis of 60 well identifiable key concepts, it was found that $75 \%$ of new learning regarded knowledge and concepts (e.g., "...that every difference, even if the least, is fundamental to classifying"; "...that all living beings are different from each other, but they have cells in common... they all have cells"; "I have learned to recognize vegetal and animal cells"; “...variability of species and cells..."; "adaptations in relationship to the environments"; "...how living being diversity originates"; "...how species evolved, their diversity and the causes of all this"; "...the common origin of living beings, evolution and species variability"). About $18 \%$ said they learned something in the activities ("I have learned to study cells with the microscope") and 7\% mentioned attitudes and motivations ("I've learned to observe differently, with a more scientific outlook").

Participation in this experience was active and attentive, interest high and the production of drawings abundant and precise. All the students were able to describe the performed activities and to emphasize their didactical aims accurately in their notebooks.

The majority of the high school students, during the conversations with us and each other, declared that they had finally connected the concept of natural selection and adaptations to "something concrete and to true experiences." For the high school classes, a more detailed evaluation of these experiences was performed in the final test.

Evaluation of the Final Tests The final test for the middle school students was composed of open-ended questions that asked for explanations (1) for the presence of cells in all living beings (the common cellular structure of living beings) and their diversity notwithstanding common characteristics (unity and diversity of living beings), (2) about the origin of the different forms of life (taxonomic biodiversity), (3) about extinction and the origin of new species, and finally (4) an explanation and comment on the last sentence of Darwin's book The Origin of Species (...whilst this 
planet has gone circling on according to the fixed law of gravity, from so simple a beginning endless forms most beautiful and most wonderful have been, and are being evolved).

I extracted and categorized the main key concepts from the answers given by two middle school classes (one class of the youngest students and one of elder students). Among 34 key concepts about cell diversity and similarity, $62 \%$ connected similarity (unity) to common origin and diversity to evolutionary processes; all the other key concepts connected diversity to different needs and functions of the cells. Regarding the origin of diversity of living beings, among 32 key concepts, $75 \%$ referred to evolutionary processes and adaptation (only one voluntary) and the remaining, about $9 \%$, to sexual reproduction that "produces diversity"; tautological explanations constituted $16 \%$. It is interesting that in the preliminary conversation and investigation of pre-existing ideas, a considerable number of middle school students attributed the origin of different forms of life to God, while in the final test nobody cited divine creation. Moreover, only one student wrote about adaptation in the sense of obligation. For the extinction and origin of new species, on 37 key concepts, $76 \%$ referred to evolutionary processes and the remaining percentage to various causes or different cell structures. Regarding the Darwinian sentence, among 40 students who answered, only seven didn't give an exhaustive answer and two students declared "I can't explain"; all the others provided valid and ample comments and wrote acceptable correct explanations about the great amount of biodiversity and about continuity of evolutionary processes.

The final test for the high school students was composed of open-ended questions about the experience on paleontological issues and extinction (first structuring concept); about the evolutionary success of insects (these animals constitute the richer group of species among all living beings); about the scientific proof of the changes of living beings and their personal opinion about this issue; and finally, the test asked students about their eventual changes in ideas, their new knowledge and learning.

All the students commented on extinction as an evolutionary process connected with environmental changes, lack of fitness, etc.; only one student wrote "...because they weren't able to adapt." This is a valuable outcome because in the pre-experience sheets, extinction was never quoted in connection with evolution. All the students were able to explain the main insect body characteristics (wings, antennas, exoskeleton, etc.) in terms of adaptation and to connect these adaptations with the insect's evolutionary success. Among the changes of ideas, I have found explicit references to evolutionary processes (15 of 47, mainly "My ideas about Lamarck and Darwin... about adaptation... natural selection... on how species adapt... have changed..."; "I've understood... my changed ideas about... diversity, evolution, extinction, natural selection... have changed and become clear"; "I have understood what natural selection and Inter-specific variability are"); but also other interesting declarations (e.g., "My ideas about my vision of man have changed."; "I now think that the superiority of man over other animals is unfounded."; "I'm excited by the point of view that man is similar to any other animal."; "My ideas about animals that populate and populated the Earth have changed... I didn't imagine that there were so many and that they were so different").

Also regarding new knowledge (what do you think/believe you learned?), the more significant answers were "...new things about Darwin and evolution ... I've learned evolution well...," but also, for example: "I've learned to look at things differently and with more attention"; "...new ways of thinking"; "I've learnt to reflect in order to find a solution." Regarding the final question about the changes of living beings, all the students furnished evolutionary explanations, supported by paleontological evidence. In all the final tests, diversity was connected to different life needs and adaptation to different life environments.

The long-term test, compiled only by the elder middle school students, was composed of six open-ended questions about the topics seen in the museum and the activities performed there. Afterwards, the students were required to write five key words about their experiences at the museum, to write what they associated the name of Charles Darwin with, why paleontology supported evolution and helped scientists to study evolutionary processes, and finally to discuss the case of the Darwin finches. The answers were analyzed and key words or key concepts were extrapolated and categorized. From the answers about topics and arguments seen in the museum, from 56 key words selected, $62 \%$ were connected with evolution (variability, diversity, relation between shape and function, natural selection, etc.), $34 \%$ with the laboratorial activities and $4 \%$ with other topics. Among the key concepts regarding the activities, from 66 key concepts $61 \%$ were connected with the laboratory activities and observation of specimens, described thoroughly and coherently; $30 \%$ regarded particular concepts or topics (we studied evolution... we explained extinction... animal diversity... animal functions...); 3\% "the tour of the museum"; $5 \%$ other activities; and $2 \%$ simply wrote "we enjoyed ourselves." Regarding the key words about the experiences performed in the Museum, among 79 key words selected from the student answers, 24\% were connected with evolution, $15 \%$ with the paleontological experience (first framing concept), 15\% with Insects and the second framing concept, $6 \%$ with animals, $5 \%$ with biodiversity, $5 \%$ with cells, $12 \%$ consisted of adjectives (beautiful, enjoying, interesting, etc.), $6 \%$ with other elements connected with laboratorial experiences, and $12 \%$ with other things. 
The total key words connected with laboratorial experiences was $48 \%$.

The key words associated with Charles Darwin were very different from the preliminary ones: Among 40 selected key words, $75 \%$ were connected with evolutionary processes, $13 \%$ referred to Darwin as a "scientist," there were 5\% other associations, and only $7 \%$ were associated with "voyage." Regarding the paleontological issues, from 18 clearly expressed answers, $72 \%$ were acceptable and exhaustive, and only five (28\%) answers were insufficiently developed. Also for the comments about Darwin's finches, among 18 well expressed and well analyzable answers, $83 \%$ were valid and abundantly developed.

To verify long-term or some unexpected outcome of the project from another point of view, teachers who took part in this experience were interviewed at the end of the school year (about two months after the respective last visit to the museum). All the teachers judged the experiences and the theoretical frameworks to be suitable. All verified interest and application in their students and developed other research and didactic products. All declared that students approached evolution in class easily and willingly: They had summarized the fundamentals of evolutionary theory simply. In their opinion, students particularly appreciated the museum setting with exhibits and biological specimens, the laboratory and creative activities, and the interactive and informal approach. In their semi-structured guided interviews, the teachers stated that the museum experience made the learning of evolutionary theory in classes easier. In particular, the high school teacher wrote in her interview that the students had had a lot of difficulties in understanding the adaptive convergence during her explanation in class, despite a great quantity of examples given by her. These students found it hard to understand that in the same environment adaptations can be convergent because the selective pressures and life needs are similar. Likewise, these students had hardly mastered adaptation issues. In addition, the teacher wrote that she could not say when or at what point understanding clicked, but after the museum experience, her students looked at animals and plants differently, and they had not been satisfied to recognize them or classify them but tried to grasp significant similarities or differences and to attribute an adaptive explanation and interpretation to them. The same teacher did not note significant differences in the students' scientific language. It is probably necessary to have greater regularity and reinforcement in the use of specific language and definitions.

Seemingly, one of the middle school teachers noted conceptual change, particularly in the understanding of biodiversity. In one of her two classes, the teacher verified that her students founded their evolutionary idea on the fossils and paleontological issues after the museum experience: The paleontological experience at the museum acted as a structuring concept for understanding extinction and change of species.

No evaluation about learning or changing ideas was possible with the adult or family visitors who attended the weekend laboratories (only one visit, about three to four hours). However, the educational experiences in a museum can be evaluated by other elements of cultural enrichment (interest and enjoyment) and by attitude and behaviors (engagement and participation). During the experiences, visitor participation was always involving, active and attentive, and the interest high; statements and manifestations of interest and satisfaction were explicit.

\section{Methodological Fundamentals and Practices}

Theoretical Frameworks This project can be considered a pilot one for the following elements and reasons. (1) The project has introduced and utilized some innovations in the theoretical frameworks, in particular as far as the choice of objectives, conceptual contents (framing concepts) and themes are concerned. The didactical pathway was designed to create a basis on which to build conceptual changes and new knowledge to make sense to evolutionary concepts, rather than/or before explaining the formal contents and assumptions of the theory. The latter is the didactic strategy more commonly applied (also in schools and museums) without checking or connecting previous knowledge or laying a basic groundwork. (2) The project has actually experimented with an interactive (and non-transmitting) use of museum resources (direct observation of specimens, participative exhibitions, integration of exhibits and laboratories). (3) The project applied constructivist didactic practices (preknowledge stimulation and assessment, interactivity, inquiry-based and problem-setting learning, discovery learning, social exchange, and collaborative learning; exploration rather than explanation or simple information giving; attention to changes of ideas and conceptual restructuring and to the awareness of them, etc.).

These theoretical frameworks are connected to a constructivist view of knowledge. According to this view, learners do not simply add new information or facts to what they already know but constantly reorganize and restructure their mental network e.g., Bruner (2002), Ausubel (1983), Driver (1989), Vygotskij $(1980,1990)$, but many other psychologists, educators, and scientists of the mind have supported and still support constructivism and create understanding as they interact with reality. Therefore, knowledge is a selfconstructed process beginning with pre-existing knowledge and experiences. Since cognitive processes are active, not passive or simply transmitting, learners should be actively involved and participate in their learning experiences and 
should be conscious of their own conceptual changes and ways of knowing (meta-cognition; Bruner 2002). From this perspective, teachers, educators, or adults in general act as "facilitators" who help to organize the learners' process of cognitive self-construction.

Some knowledge can be memorized, but fundamental knowledge needs active constructivist mental processes. As a consequence, simple explanation or transmission of knowledge generally is not sufficient or suitable for restructuring pre-existing information or for activating conceptual changes. New information and concepts risk remaining "on the surface" and not being included in the conceptual network. As a consequence, they cannot be utilized in reasoning. In particular, for fundamental and structuring themes and subjects of knowledge such as evolution, we have sufficient proof of the resistance to conceptual change and of common ideas prevailing over scientific ones, in spite of school teaching.

To obtain conceptual restructuring about evolution, we need active and participative mental processes. Accordingly, in "Darwin 2009," the didactic methodologies were constructivist and engaging, aiming at the revision and improvement of the participants' conceptual frameworks by means of personal inquiry and study, practical experiences, and sociocultural exchange, as in a true research process. Conceptual change is more likely to occur when students can experience the phenomena directly (Sinatra et al. 2008; Dole and Sinatra 1988); research on conceptual change suggests that the degree of engagement, that is, how deeply students become involved in the content through discussion, debate, dialogue, and/or experimentation, relates to the likelihood of change.

Since awareness of one's own ideas is the basis of revision and restructuring of knowledge, in the "Darwin 2009" project, all the discussions and guided practical experiences started from participants' previous knowledge and ideas, through questions or problematic issues. These discussions were also a point of strength in this didactic project because they revealed misconceptions and ideas that could hinder understanding and learning.

Rather than as "informers," the other museum operators and I acted as "organizers" of the visitors' (students and general public) cognitive processes, stimulating them to recall their knowledge, to reflect on their language and definitions, to observe and experiment, to verify the congruence and reliability of their points of view, and to shift from common sense and lay knowledge to scientific perspectives. The strategy was to stimulate questions, curiosity, doubts, and interests to which evolutionary theory could then provide a satisfying answer.

Scientific teaching includes the use of laboratory experiences in didactic practices to favor comprehension, to involve learners, and to allow them to approach scientific research methods. In particular, laboratory activities make the understanding of scientific thinking and biological evolution easier (Pievani and Serrelli 2008). From a constructivist perspective, we integrated museum observatory exhibits and small laboratories for practical experimentation. Interactive, participative exhibits which include visitors (the formula "inclusive museum" has, by now, become a part of museum language) come highly recommended (Falchetti 2007; Hein 1995; Myrivili 2007), since they are better at engaging visitors and consistent with the recommended constructive and active vision of museums. In "Darwin 2009," the laboratory was conceived not only as a space where experiments could be done but also as an experimental procedure and as a model for reasoning (inquiry-based and problem-setting learning), like in a real scientific study.

Theoretical Basis for the Evaluation A constructivist approach to knowledge could require new or non-traditional evaluative principles and methods and could find an objective evaluation unfitting. However, it is possible to adopt reliable forms of evaluation. Constructivist didactical processes are based on adaptable, non-rigid objectives, on flowing and sometimes unforeseeable pathways, and on personal ways of thinking and knowing. They are not arranged in fixed phases or sequences. Therefore, the use of more paradigms and different methodological strategies of evaluation may allow a deeper comprehension of these educational events. Thus, in this project, I have experimented with original strategies of evaluation on the basis of the following theoretical frameworks.

Scientific "complexity theory" and "systems theory" have also influenced the psycho-educational field and revealed the dynamic, complex character of educational events. Learning processes do not develop with causallinear logic. Constructivist epistemology has emphasized autonomy of the learner toward environmental input. Learners do not learn deterministically but select stimuli actively from the context and integrate the ones significant for him/ her into his/her mental framework. As a consequence, didactic strategies endowed with inherent educational qualities do not exist. It is not guaranteed that specific educational input determines a definite and expected output.

If educational processes must be considered as inherently complex systems, then linear "objective" and quantitative evaluations can be insufficient and inadequate. The unpredictable complexity of the educational experience suggests the inappropriateness of constricting evaluation into rigid theories, pre-defined tools, and pre-established interpretations. Comprehension of the educational process is "limited" if analyzed using many common epistemologies and tools. Pre-defined inquiry procedures reduce the complexity (and this could be convenient), but they do not allow true comprehension of the educational processes. A post-modern 
perspective suggests employing a constructivist approach that includes qualitative, participative, and shared methods of evaluation able to assess educational processes rather than (or not only) formal and analytical objectives and outcomes. In particular, constructivist, interpretative evaluation (Lagsten and Goldkuhl 2008; Symons 1991; Avgerou 1995; Jones and Hughes 2001) aims to understand the dynamics and multiple perspectives of those involved in the educational process through participants' ways of thinking, ideas, opinions, and feelings toward educational themes and experiences.

Museum educational experiences are especially complex to evaluate if compared to scholastic ones because in a museum, inputs and variables are more numerous and different and contexts are less formal; communicative didactic strategies are individual; and students' reactions are more personal, free, and unpredictable. Defining outcomes and verifying the influence of single factors is difficult. Moreover, more recent evaluation strategies also tend to evaluate non-conceptual outcomes. For example, the Institute of $\mathrm{Mu}-$ seum and Library Science (IMLS, 1999), in its "Impact Categories" defines learning outcomes as benefits to people, specifically achievements or change in skill, knowledge, attitude, condition, or life status for program participants (Pekarik 2010). The National Science Foundation's Informal Science Education Program developed a relational database to facilitate the recording of project outcomes for exhibitions, a Project Monitoring System. Potential users of the project are required to identify unintended outcomes using six "impact categories": awareness, knowledge or understanding, engagement or interest, attitude, behavior, skills; plus, other (Friedman 2008). A similar categorization of outcomes for museums, known as generic learning outcomes (GLO, http://www.Inspiringlerningforall.gov.uk/ toolstemplates/genericlearning/index.html), was developed in Great Britain, by the Museum, Libraries and Archives Council. The five categories of GLO are: knowledge and understanding; skills; attitudes and values; enjoyment, inspiration, and creativity; and action, behavior, and progression. Pekarik (2010) criticizes outcome-based evaluation in museums because - provided that objectives are clearly defined and outcomes clearly discernible - "The strength of outcome-based evaluation lies in its conceptual simplicity... but outcome frameworks are very likely to lead-by the coercive rationality of the logical model - to measurements, and these measurements, necessarily narrower than the outcomes themselves, further restricting the range of what staff believes an exhibition can accomplish." Outcome-based evaluation is lacking in synthesis and does not consider outcomes such as other knowledge. Measurements are likely to be indirect, subjective, and vague; and nothing is said about the ideal time at which to measure an outcomeshould a behavior change be measured immediately upon exit from the exhibition, a short while later, or much later? Finally, since museum visiting is likely to be only one of a series of interrelated activities that might have a role in determining the outcome of a visit, how can you control for these confounding variables?

In "Darwin 2009," consistent with the constructivist perspective and theoretical frameworks explained above, I have utilized qualitative content analysis and analyzed not only performance outcomes but also the trend of the educational processes and variables such as attitudes, interests, engagement, participation, etc. I have tried to balance evaluation between interpretive (personal ideas opinions, perceptions, etc.) and outcome-based criteria (conceptual change, skills, behaviors, interests, engagement in the experiences, etc.). I have also considered new knowledge as changing of ideas (conceptual restructuration) and as performance-both changing of ideas and new knowledge acquisitions. I have considered it fundamental to document and analyze student perception or awareness of changes and how the changes happened. For these reasons, students were constantly required to make notes of eventual changes of ideas, new learning and knowledge, interests, etc. in their notebooks and conversations were considered to be an interesting element of evaluation.

Mine could be considered a particular case of phenomenographic analysis. Phenomenography is a qualitative evaluation method based on the assumption that "The educational enterprise ideally seeks to improve learners' ability to think - to create novel approaches, ideas, and solutions - and not simply to perform well" (Micari et al. 2007 , p. 459). In this view, evaluation would provide meaningful information about how well students are learning; assessment must capture student thinking, and not just student performance. Rather than measuring learning outcome as performance, in phenomenographic studies, we are measuring learning outcomes as change in conceptions of or approach to the learning object (Micari et al. 2007).

Change in conceptions can be thought of as learning that enables the learner to experience a phenomenon in a way she or he has not been able to experience it previously (Marton and Booth 1997). Generally, in phenomenographic studies, people are assumed to move from less to more sophisticated conceptions of a particular phenomenon in hierarchical fashion (Marton and Booth 1997). This occurs through experiencing the object of learning in new ways and integrating the contrast between the current and former understanding into one's conception of the object of learning. As the individual learns, she or he also gains awareness of these differences in perspective, or of the variation in experiencing the phenomenon (Trigwell 2000).

Measuring this subtle and complex change requires an educational evaluation model that reveals how learners think and measures change in their thinking over time. 
Phenomenography is a method and accompanying set of theoretical assumptions that seeks to identify variation in the ways people conceive of and approach learning-related experiences (Marton and Booth 1997). This method can be used to evaluate a learning program's effectiveness and provide guidance tailored to the learner (Micari et al. 2007).

\section{Discussion}

Every educational process is different and connected with the context, learners, and participants. This is valid also for "Darwin 2009." However, some generalizations can be made about this experience. Three main issues can be discussed: (1) the museum as communicator and facilitator in the learning of evolution, (2) learning of evolution by constructivist, interactive frameworks and strategies, and (3) repeatability of the project and its value outside the Zoological Museum.

Point 1. From the point of view of the museum's educational role, the "Darwin 2009" project has been useful for exploring new methods and didactic practices regarding evolutionary themes, both for school and other museum visitors. Concerning the goal of stimulating citizen interest, numerous families and general visitors participated in the project on weekends for the whole period the exhibition was open (April-November 2009). The experience was greatly appreciated (as recorded in the book of visitors' comments and from final interviews made by museum educators) and "word of mouth" brought many new visitors to the Museum (in 2009, we noted an increase of 7,000 visitors compared to the previous year, with the greatest increase corresponding to the length of the exhibition on evolution). This is a favorable outcome because awakening citizen interest in evolution was one of the aims of "Darwin 2009." The themes-wideranging and less framed by formal structures-and the practical experiences allowed all visitors to participate in the discussions and activities. The working methods and communication were suitable for various ages and educational levels but also emotionally engaging and favorable to interactions among the visitors-adults and children alike. In fact, they were all stimulated to work together. The welcoming of family and friendly interaction is one of the first wishes of our public (Falchetti 2007) and an element of satisfaction for the museum visitors, but it is useful to remember that social relationships influence emotions and contribute to learning (Vygotskij 1980).

Regarding schools, 51 school classes participated in this didactical project (besides the pilot classes) and attended the exhibits and laboratories. Again, "word of mouth" generated a large quantity of requests, many of which, unfortunately, remained unanswered (given the brief time allowed in the museum's program for this exposition and the schools' summer holidays). This project met with great success within the Roman schools, surely for the "curricular" topic and for the exploitation of the museum resources, but also because the communication strategies did not use a scholastic transmitting dynamic. According to random interviews of teachers and students in the museum, the direct participation, engagement, "active exhibits," and freedom to explore and experiment were the most appreciated elements. The thematic choices, for all the teachers, were valid both for the interest they sparked and for the acquisition of new knowledge.

The "Darwin 2009" project was flexible and adaptable to all ages and school levels (primary school did not take part in the chromosome experience) because it was aimed at building framing concepts and not at "transmitting" information or explanations about evolution; this was possible also without precise previous scientific knowledge

The "Darwin 2009" project confirms that (1) museums have a high probability of success in introducing and involving citizens in evolution, moving from an "informative museum" to a "constructive museum" and if they apply a didacticepistemological reflection in the planning of the exhibition. They have a quantity of unique resources for this aim. Many museum expositions are designed daily to illustrate biological evolution, but few studies - maybe none in Italy - exist on the relapse, the effects of the acquisition of new knowledge or the modification of visitors' ideas, attitudes, skills, and behaviors. New exhibitions are planned following constructivist approaches (a lot of museum designers master these pedagogical models and choose themes and techniques that help visitors to self-construct knowledge). But many exhibitions still reflect traditional transmitting "deficit model" (Wynne 1995) and mediation strategies as synthesis and simplification of contents to provide information on formal arguments of evolution, without supporting them with framing concepts. Now we have many proofs of the difficulty to transfer or juxtapose knowledge, in particular on 
evolutionary themes. The transmitting-informative approach does not facilitate reflection, self-inquiry, involvement, or the conceptual change necessary to master evolutionary thought. However, we have only a few data on the impact of exhibitions; it is worth while carrying out specific research about it.

Point 2. Learning evolution through constructivist strategies and framework: Only a few didactic experiences on evolution have a real constructivist nature and aim at conceptual change, notwithstanding that the latter is strongly recommended and considered necessary to understanding evolution. This didactic project can be considered a successful experiment on constructive strategies for understanding evolution. Conscious changes of ideas and approaches, of attitudes and interests in Charles Darwin (not only a traveler...) and evolutionary processes were documented by the test answers and conversations of the students in the pilot classes. An interesting increase and improvement in key words and key concepts has been documented compared to the initial ones that support conscious construction of new knowledge and restructuring of pre-existing knowledge.

The choice of working on and by means of framing concepts was revealed as valid. The four themes appear consistently reliable as structuring concepts and valid for activating interests and supporting knowledge construction or revision. The thematic issues were able to rouse curiosity and "good" questions and to guide participants to various points of the theory of evolution for a plausible and convincing explanation. All the four framing concepts turned out to be suitable for approaching the issues of evolution, in particular adaptation and natural selection, as has been shown by the students' conversations, answers to the questionnaires, practical productions, and by the declarations of the teachers in their interviews. In particular the first, second, and third seem to favor "evolutionary thinking."

The variety of the themes and flexibility of the didactic objectives, in comparison with other rigid didactic projects, increased the chances to engage the students and to stimulate their different knowledge and motivation. The active and involving didactic strategies probably provided a suitable setting that favored the necessary interest, participation, and engagement to activate autonomous construction of knowledge.

Non-transmitting strategies and practical experiences were able to stimulate curiosity, to support research pathways, and personal inquiry, and reflection. The various experiences stimulated learning and conceptual changes (obviously in different ways and intensities, according to individual student diversity) and facilitated the approach to evolutionary theory in classes (as declared by the teachers). All these results can be considered to be positive outcomes from a constructivist point of view. In consideration of the short time available, compared to that provided in the scholastic setting, the outcomes are satisfactory, both in the cognitive and emotional affective fields. In particular, the emotional outcomes are to be estimated, given their attested influence on learning (performance and nonperformance). Emotions and motivation are now recognized as critical or even determining for the likelihood of change (Dole and Sinatra 1988; Sinatra and Pintrich 2003). The work in class was probably also facilitated by the acquired positive attitude toward evolutionary issues.

The non-rigid and non-constrictive evaluation is suitable for showing subtle and deep conceptual change (otherwise unknown by means of performance-objective analysis) and for revealing the different ways of thinking, the process and causes of the conceptual changes, and the impact and value of the different experiences.

A critical point of this educational experience aiming to build a basis of comprehension of evolution or improving knowledge of it has been "what answers to give to the students' questions? when? How far to extend explanation and formal knowledge in answer to their questions?." This is a typical doubt arising from constructivist pathways aiming at self-construction of knowledge and depending on the unpredictable course of their "semi-free/individual" educational processes. In a constructivist project, teachers/operators' pathways co-evolve with those of the students. In the "Darwin 2009" project, when the students' questions were explicit, the museum educators provided an evolutionary explanation, also by means of maieutic procedures to aid students in remembering what they already knew about these topics. However, these procedures were different in the different classes and school levels. In some cases, we provided precise answers; in other cases (especially with the primary school students), we left the commitment to deepening the discussion of evolutionary theory in class to the teachers.

Point 3. Given the success of this experience both on the cognitive and affective levels, the "Darwin 2009" 
project could be used as a reference not only for museum exhibitions on biological evolution but also for scholastic "non-transmitting" didactic pathways. "Darwin 2009" was carried out in a Zoological Museum, and it has been successful certainly thanks to the particular context and museum's facilities. However, the conceptual pathway has an inherent validity and can also be utilized in schools and in extra-museum experiences. The structuring concepts can be approached by means of discussions and experiences supported by observations of animal and vegetal specimens easily found also outside museums.

The final consideration is that it is convenient to carry out further "brave" constructivist experiments in teaching evolution in school and museums, even if these require the abandonment of consolidated and reassuring practices.

Acknowledgments A special thanks to Emanuele Serrelli for his precious critical revision of the manuscript. Thanks to all the educational Operators of Myosotis Group that collaborated in the realization of the exhibition and in the didactic activities and to Nicola Margnelli and Valeria Bodò, who collaborated in the didactic visits and the recording of the research data.

\section{References}

Aroua S, Coquidè M \& Salem A. Treatment of finalistic obstacle related to biological evolution. Study of teaching case in Tunisia. Seventh ERIDOB Conference; 2008.

Ausubel DP. Educazione e processi cognitivi. Franco Angeli Ed, Milano; 1983. 832 (Orig. title Educational Psyghology: A Cognitive View)

Avgerou C. Evaluating information systems by consultation and negotiation. Int J Inform Manag. 1995;15(6):427-36.

Bardapurkar A. Do students see the "selection" in organic evolution? A critical review of the causal structure of student explanations. Evol Educ Outreach. 2008;1:299-305.

Bateson G. Mente e Natura. Adelphi Ed.: Milano;1999. 313 (orig. Title Mind and Nature)

Bertolini B. La biologia e Galileo: per un discorso sui metodi. Paravia Ed. Ipsilon. 1992; 11:18-20.

Bishop B, Andersen CW. Student conception of natural selection and its role in evolution. J Res Sci Teach. 1990;27:415-27.

Boillot-Grénon F. Clarifier les représentations des partenaires de l'éducation relative à l'environnement. Aster. 1999;29:61-80.

Bruckmann M. L'insegnamento della biodiversità per l'educazione alla conservazione della natura. Tesi di Laurea. Facoltà di Scienze Mat. Fis. e Naturali, Università La Sapienza (Roma) Ac. Year 2008-2009; 2009.

Bruner J. La cultura dell'educazione. Milan: Universale Economica Feltrinelli; 2002. p. 233. orig. title: The Culture of Education.

Caravita S. Ambiente come intreccio. Cooperazione Educativa. 2006;55(2):70-8.

Demastes SS, Settlage JJ, Good R. Student's conception of natural selection and its role in evolution: cases of replication and comparison. J Res Sci Teach. 1995;32(5):535-50.
Dole JA, Sinatra GM. Reconceptualizing change in the cognitive construction of knowledge. Educ Psychol. 1988;33(2/3):10928.

Driver R. Changing conceptions. In: Adey P, editor. Adolescent development and school science. London: Falmer; 1989. p. 61-84.

Falchetti E. Insegnare la biodiversità. Rome: MIUR, Museo Civico di Zoologia; 2006.

Falchetti E. Costruire il pensiero scientifico in Museo. Rome: Museologia Scientifica Memorie ANMS 1; 2007. p. 255.

Falchetti E. La scienza sistemica interpreta l'ambiente: dall'ecosistema al paesaggio. Riflessioni sistemiche, Rivista AIEMS: 2, febbraio; 2010.

Falchetti E, Visco C. Dall'ecosistema al paesaggio. In Falchetti E La scienza della complessità spiega l'ambiente. Rome: Museo Civico di Zoologia Ed; 2008. p. 24-86.

Falchetti E, Tranchida F, Visalberghi E. I Primati e l'evoluzione biologica. Un approccio costruttivista all'educazione scientifica. Rome: CNR; 1999. p. 126.

Friedman A (2008) Framework for evaluating impacts of informal science education projects. National Science Foundation. http:// www.insci.org/resources/Eval_Framework.pdf. Accessed 3 Oct 2009

Gagliardi R. Los conceptos estructurales en el aprendizaje por investigation. Ensenanza de las Ciencias. 1986;4(1):30-5.

Gagliardi R. Le rappresentazioni mentali degli studenti e i concetti strutturanti che ne permettono la trasformazione. In: Atti dei seminari di didattica delle scienze. Turin: CIRDA; 1989.

Goldstein AM. Evolution by example. Evol Educ Outreach. 2008;1:165-71.

Hein G. The constructivistic museum. J Educ Mus. 1995;15:1-15.

IMLS Document perspectives on outcome based evaluation for libraries and museums. http://www.imls.gov/applicants/basics.shtm

Jones S, Hughes J. Understanding IS evaluation as a complex social process. A case study of a UK local authority. Eur J Inf Syst 2001;10:189-203.

Kyle WC (Ed.) The teaching and learning of biological evolution. J Res Science Teach 1994;31:153

Lagsten J, Goldkuhl G. Interpretative IS evaluation: results and uses. Electron J Inform Syst Eval. 2008;11(2):97-108.

Maniaci A. Sulle tracce dell'evoluzione. Lo studio di un caso: gli Uccelli. Tesi di Laurea. Univ. di Roma "La Sapienza", Fac. Scienze Mat. Fis. e Naturali, Acad. 1992; Year 1991-1992.

Marton F, Booth S. Learning and outcomes/awareness. Mahwah: Lawrence Erlbaum; 1997. p. 224.

Mayr E. L'unicità della biologia. Milan: Raffaello Cortina; 2004. p. 246 (orig. title What makes unique biology?)

Mead LS, Scott EC. Problem concepts in evolution part I: purpose and design. Evol Educ Outreach. 2010;3(1):78-81.

Micari M, Light G, Calkins S, Streitwieser B. Assessment beyond performance. Phenomenography in educational evaluation. American J of Evaluation. 2007;28(4):458-76.

Myrivili E. Performativity, interactivity, virtuality and the museum. Museol e-J 2007;4:5-18

Nadelson LS. Preservice teacher understanding and vision of how to teach biological evolution. Evol Educ Outreach. 2009;2(3):490-504.

Pekarik AJ. From knowing to not knowing: moving beyond "outcomes". Curator. 2010;53(1):105-15.

Pievani T. Introduzione alla filosofia della biologia. Rome: Laterza; 2005. p. 260.

Pievani T, Serrelli E. Education in evolution and science trough laboratory activities. Evol Educ Outreach. 2008;1:541-7.

Prinou L, Halkia L, Skordoulis C. What conceptions do Greek school students form about biological evolution? Evol Educ Outreach. 2008;1:312-7.

Rees PA. The evolution of textbook misconceptions about Darwin. J Biol Educ. 2007;41(2):53-5. 
Richards R. Philosophical challenges in teaching evolution. Evol Educ Outreach. 2008;1:158-64.

Sinatra GM, Pintrich PR. Intentional conceptual change. Mahwah: Erlbaum; 2003. p. 479.

Sinatra GM, Brem SK, Evans EM. Changing minds? Implications of conceptual change for teaching and learning about biological evolution. Evol Educ Outreach. 2008;1:189-95.

Symons V. A review of information systems evaluation: content, context, process. Eur J Inform Syst. 1991;1(3):205-12.

Tranchida F. Dalle Proscimmie alle Scimmie Antropomorfe: un percorso didattico sull'Evoluzione. Tesi di Laurea Univ. di Roma "La Sapienza", Fac. Scienze Mat. Fis. e Naturali, Ac. Year 19951996; 1996.

Trigwell K. Phenomenography: variation and discernment. In: Rust C, editor. Improving student learning. Proceedings of the 1999 7th
International Symposium. Oxford: Oxford Centre for Staff and Learning Development; 2000. p. 75-85.

Valente A, Cerbara L, Caravita S, Luzi D. Conceptions on evolution in teachers and future teachers: results of an Italian investigation. XIII IOSTE Symposium, the Use of Science and Technology Education for Peace and Sustainable Development. September 21-26, Kusadasi/Turkey; 2008.

Vygotskij L. Pensiero e linguaggio. Bari: Biblioteca universale Laterza; 1990. p. 428. Orig. title Though and language.

Vygotskij L. Il processo cognitivo. Turin: Bollati Boringhieri; 1980. p. 200 (orig. Title. The Development of Higher Psychological Processes)

Wynne B. Public understanding of science. In: Jasanoff S, Merkel GE, Petersen JC, Pinch T, editors. Handbook of science and technology studies. London: Sage; 1995. p. 361-88. 